\title{
Accompanying Partners of International Students: Reflections on Three Issues
}

\author{
Dan Cui \\ University of California, Berkeley, \& University of British Columbia \\ Nancy Arthur \\ University of Calgary \\ José F. Domene \\ University of New Brunswick
}

\begin{abstract}
This paper reviews and critiques the existing literature on accompanying partners of international students (APIS), who are often an ignored population in programs and services for the internationalization of Canadian higher education. Particularly, we identify three issues. First, we argue that current research on this group overwhelmingly focuses on their social and cultural adaptation difficulties while ignoring their agency in dealing with life challenges in the host society. Second, we note that research on this population should go beyond an overemphasis on gender, to include a comprehensive analysis of how gender intersects with other unequal social relations, such as race and class, in contributing to the complexity and multiplicity of their lived experiences. Finally, we suggest that rather than conflating APIS with trailing partners of expatriates or immigrants and treating them as a homogenous group, researchers should do more to address their heterogeneity from an anti-essentialist approach.
\end{abstract}

\section{Résumé}

Cet article examinela littérature existante sur les partenaires accompagnateurs d'étudiants internationaux (PAEI), une population souvent ignorée dans 
les programmes et services pour l'internationalisation de l'enseignement supérieur canadien, et formule quelques critiques sur le sujet. On y relève trois points en particulier. Dans un premier temps, nous postulons que les recherches actuelles sur les PAEI se concentrent exclusivement sur leurs difficultés d'adaptation sociales et culturelles, et ignorent leur entremise dans la gestion des défis de la société d'accueil. Deuxièmement, nous remarquons que les recherches sur les PAEI doivent se poursuivre au-delà de la trop grande importance accordée au genre, et proposer une analyse complète sur la façon dont le genre s'entrecroise avec d'autres facteurs d'inégalités sociales, tels l'ethnie et la classe sociale, qui contribuent à la complexité et à la multiplicité de leurs expériences de vie. En dernier ressort, nous suggérons qu'au lieu d'amalgamer les PAEI avec le flux de partenaires d'expatriés ou d'immigrants et de les traiter comme un groupe homogène, plus de recherches doit mettre en exergue leur hétérogénéité dans une approche anti-essentialiste.

International students have historically played an important role in the internationalization strategies of Canadian higher education (Arthur, 2004). Recently, the profile of international students has been raised in light of their crucial role in contributing to Canada's economy, industry innovation, and labour market planning, as well as its social and cultural diversity (Advisory Panel on Canada's International Education Strategy, 2012). Across the world, Canada ranks as the seventh most popular destination for international students and derives more than $\$ 8$ billion annually from international student expenditures, including tuition and living expenses (Canadian Bureau for International Education [CBIE], 2013). Among the 265,377 international students in Canada at the time of the CBIE report, $55 \%$ were studying at universities and $26 \%$ at a trade school or another postsecondary institution (CBIE, 2013). Yet despite the large presence of international students in higher education, most research tends to focus on international students themselves, while little is known about the lived experience of their partners, primarily women, who accompany international students to their country of education. This research gap raises critical social justice issues, given the fact that many international students' accompanying partners are well-educated professionals in their home countries but experience adaptation difficulties, a lack of social support, career downgrading, and psychological distress in their new environment (Chen, 2009; Cho, Lee, \& Jezewski, 2005; Kim, 2012). Their status as neither students nor immigrants renders them "invisible sojourners" (de Verthelyi, 1995) from both academic and employment perspectives.

In appreciation of the social and relational context of international students' transitions, we conducted a systematic review of the existing literature base to identify, describe, and analyze the main issues and concerns facing accompanying partners of international students (APIS) studying in Canada. The literature almost exclusively focuses on the experiences of women accompanying partners. As such, in this article, we define APIS as women who move to another country to accompany a partner who is studying as an international student. Although some of these women may subsequently become students themselves or find employment in the new country, employment or their own education are not typically the primary motivation for them to move to a new country. Rather, they are accompanying their partners, who are engaged in international studies. 
We identify three main issues with the existing studies of women partners of international students. First, we argue that existing research tends to focus overwhelmingly on their social and cultural adaptation difficulties while ignoring their agency and resiliency in dealing with challenges in a new living environment. Second, the influences of gender on their adaptation process are often highlighted, while these women's other social positions (e.g., race and class) are surprisingly ignored or minimized. Researchers need to examine how gender intersects with other socially constructed differences that contribute to such women's renegotiation of family relations and career trajectories, and their experiences in the new cultural environment. Third, we note the lack of research with this population and interrogate the assumptions made in comparing their experiences to trailing partners of expatriates or immigrants. Although these populations may share some commonalities regarding adaptation issues, the distinct situation of APIS requires unique attention and services from researchers and policy makers. We also suggest specific directions for future research. In so doing, we provide readers with a list of central and sub-research questions to address the three issues we raise with respect to existing research. Finally, we conclude by highlighting that more research is needed to strengthen the visibility of APIS. It is critical to provide adequate support services and to recognize the important roles that they have in our country's long-term goals of internationalizing higher education and recruiting highly skilled immigrants.

\section{Literature Review Strategy}

This review draws on literature from three interrelated but distinct fields: education, counselling psychology, and human resources and management. The data collection process involved three major steps. First, a research assistant searched the databases of Academic Source Premier, Business Source Premier, the Education Resource Information Center, and PsychINFO for relevant articles, book chapters, and dissertations published from 1990 onwards, using the following search terms: international students and partners/spouses, international students and romantic relationships, international students and family, accompanying partners/spouses, and trailing partners/spouses. Additional sources were identified by examining the reference sections of obtained materials. This literature search yielded 61 publications addressing the topic of APIS and/or accompanying partners during international employment, which we systematically examined in terms of five major elements: (a) topics/issues, (b) research questions, (c) methods, (d) findings and conclusions, and (e) future directions for research. For each article, the first author and the research assistant read and summarized content relevant to these five elements by focusing on the authors' explicit statements, placing our summaries in a summary table. Appendix A provides a sample of one entry in the summary table. From this table, we identified key trends and ideas related to the research question of what themes have been absent in the existing literature base. More specifically, the topics and research questions provided initial indications of the focus of the publication, and these indicators were then compared and synthesized to generate major themes. As needed, we examined the full article to clarify uncertainties and to confirm the nature of the emerging themes. The initial themes were revised to reduce redundancy and to align common themes together. In the end, three overarching themes emerged from our review: (a) adaptation difficulties; (b) gender issues; and (c) the conflation of international students' partners with other populations. 


\section{Issue One: Adaptation Difficulties and Human Agency}

\section{Adaptation Difficulties during the Cross-Cultural Transition}

Cultural and social adaptation difficulty was the most frequently addressed topic in the literature about APIS. Among a variety of adjustment issues, we identified five themes that drew more academic attention than others: (a) language barriers and cultural conflicts (Kim, 2012); (b) lack of social networks (Myers-Walls, Frias, Kwon, Ko, \& Lu, 2011); (c) psychological distress (Chen, 2009; Cho et al., 2005); (d) lack of support services and programs at the institutional level (Schwartz \& Kahne, 1993); and (e) parenting issues (Kim, 2012; Myers-Walls et. al., 2011). These issues intersect with each other in complex ways that contribute to the multi-layered adaptation difficulties that international students' partners may encounter in the host country.

Language proficiency as a key to social adaptation. Language barriers were identified as one of the most salient problems for APIS whose native language is not English (Kim, 2012). In her study with Korean APIS in the United States, Kim reported that participants' inability or limited capacity to speak English rendered them reserved in social interactions, increased their dependency on their husbands in daily life functioning (e.g., answering phone calls), and resulted in psychological stress, such as feeling "useless and empty" (p. 758). In addition, lack of English proficiency restricts APIS from accessing services and programs provided by mainstream social institutions and from expanding social networks with local people. A lack of language proficiency also has impacts for their career development. They may not be able to seek educational opportunities at postsecondary institutions as their partners do (de Verthelyi, 1995), or they may be restricted from gaining employment in the local labour market.

Language problems are further compounded by different values and beliefs across countries, in terms of what are counted as "normal" social relationships between human beings and what are regarded as appropriate social behaviours in the public space. These cultural and ideological differences may cause confusion during the spouses' interactions with individuals from their host country. For example, Kim's study (2012) reported that Korean APIS's ways of behaving that were intended to show respect for seniors and authorities were misunderstood by American doctors as a manifestation of low self-esteem.

Lack of a social support network. Some APIS reported they received inadequate support from their husbands, who themselves also struggled with various adjustment issues, especially academic pressure in a new environment, thereby leaving limited time and energy for the family (Myers-Walls et al., 2011). Others noted the loss of their social networks, such as extended family members, relatives, and friends, on whom they used to depend for emotional and instrumental support. Financial constraints, visa restrictions, family responsibilities, and geographical distance may prevent international student families from traveling back to their home country (de Verthelyi, 1995). Although modern technology greatly facilitates communication among people in different parts of the world, some women partners are concerned that sharing emotional difficulties with parents may cause the latter excessive worries and anxieties (Cho et al., 2005), or that sharing their needs with other APIS around them may make them vulnerable to malicious gossip (Kim, 2012).

Psychological stress. As a result of the intersections between language proficiency and lack of social adaptation, many APIS have reported suffering from psychological 
stress, such as loneliness, depression, frustration, anxiety, insomnia, panic, nervousness, anger, and helplessness (Chen, 2009; Cho et al., 2005; Kim, 2012). The demands of an academic program often mean that international students are overtaxed and may not be able to spend a lot of time with their partners, a reality that can exacerbate feelings of isolation and depression for one or both partners (Arthur, 2016). When their partners react in frustration, marital tension and conflicts often result. Some women studied by Cho and colleagues (2005) experienced an identity crisis, self-blaming for feeling inadequate. Without a social support network, they found themselves stuck in situations where "there was no place to go when they quarreled with their husbands," and "there was no one to confide when their inner emotion conflict[ed]" (p. 904).

When dealing with adaptation stress during cross-cultural transitions, many APIS may be unwilling to seek formal counselling assistance. This can be due to lack of knowledge about local resources or due to perceived stigma, given that in many countries, psychological illness is negatively regarded as a shame to both individuals' and their families' reputations. Therefore, counselling may not be viewed as a resource to increase coping capacity (Arthur, 2016). In other cases, language problems and unfamiliarity with psychological treatment may prevent this group from fully benefiting from such services. For example, in Kim's (2012) study, one international student's wife with severe depression reported that the local healthcare service did not work for her, as she could not describe her depression symptoms and related experiences in English. She disappointedly recalled: "I did not return after the first meeting" (p. 760). This example suggests that the complexities of APIS's experiences need to be better understood by healthcare professionals, who may be consulted for either physiological or psychological concerns that often manifest as culture shock or more serious mental health issues during cross-cultural transition (Arthur, 2016).

Falling between the cracks of institutional services. As seen from the above examples, lack of relevant services and programs at the institutional level that are specifically targeted at this population also contributes to the adaptation difficulties of APIS. Unlike international students, who are regarded as legitimate members within the university community, their partners are usually considered "outsiders," whose well-being is viewed as beyond the responsibilities of universities (de Verthelyi, 1995). As Schwartz and Kahne (1993) noted, "Although these women are in the [international student] community, they are not of it" (p. 454). Therefore, there are few services and programs available to assist this population. For APIS, accessing available institutional support is further restricted by other factors, such as lack of information about relevant programs, financial constraints, and lack of childcare support. For example, information about support services may be circulated directly to international students, who are then positioned as gatekeepers for their partners, determining whether to share the information that they may see as relevant, or not. Additionally, international students' partners may be reluctant to become involved in social activities organized by the university, due to financial concerns (Schwartz \& Kahne, 1993). Transportation may be another issue limiting their ability to attend campus-based social events, for those who live off campus and do not have a car or a student transit pass. Lack of childcare support is an additional barrier to accessing services and programs (Martens \& Grant, 2008; Schwartz \& Kahne, 1993).

Parenting demands. Parenting issues add another layer of adaptation difficulty for international student families with children. Cho et al. (2006) found that most APIS in 
their study felt stressed and exhausted from taking care of children by themselves, due to lack of childrearing knowledge, experience, and support from their parents or other family members that they would have received in their home country. Fonseca (1995) discussed factors related to parenting stress and satisfaction among international students' families. Educational opportunities, English language acquisition, and access to good supplies and resources such as baby foods, playgrounds, and children's books were listed as benefits associated with studying abroad, while the loss of their own culture, values, and language, especially among their children, was identified as parents' primary concerns.

The last point was echoed in Kim's (2012) study. The Korean APIS reported experiencing conflict with their children who embraced the cultural values and beliefs of their host country that were incongruent with their traditional Korean ones. This cultural conflict was further exacerbated by communication barriers between parents and children, with the latter quickly learning to speak English and using it as the main communication tool while the former did not. As a result of the differential rate of acculturation between children and their parents, feelings of ambivalence often arise: on the one hand, international student parents hope their children can maintain their home language and culture, while on the other hand, they also expect the children to quickly integrate into the new living environment and benefit from the new culture. Furthermore, these parents have also been found to worry about their children's re-adaptation if they anticipate returning to the home country (Myers-Walls et al., 2011).

\section{Beyond the Pathological View: Acknowledging Human Agency}

Undoubtedly, many APIS encounter a variety of structural constraints during their social and cultural adaptation process in the host society. As a general rule, the greater the differences in cultural expectations and norms between the home and host cultures, the greater the adaptation stress that individuals experience during cross-cultural transitions (Arthur, 2016). However, it is also important to realize that individual agency is always present in this transition period. Rather than overemphasizing structural constraints in a deterministic way, researchers need to view international students' partners as reflective and agentic individuals who can actively shape their own experiences to varying degrees. In coping with life challenges and social inequity, some people choose to complain and feel defeated while others learn to resist and grow. As Wills (1977) argued: "social agents are not passive bearers of ideology but active appropriators who reproduce existing structures only through struggle, contestation" (p. 175). Existing studies tend to overwhelmingly focus on structural constraints and adaptation difficulties, while ignoring the strengths and agency demonstrated by this group during the cross-cultural transition. An exception was found in Chen's (2009) study. Unlike other APIS, who may suffer from psychological depression in a situation of loneliness, one participant in her study reported:

I did not allow myself to be depressed. I never allowed myself to get depressed. So I would get up in the morning, feel sad, then I would say: OK, I need to do something ... And I want to start life and enjoy life and not think of my life and say: oh this is my life, I am going to die. I don't want to do that. I want to make, make [stressed] something of my life. (p. 222) 
Chen found some participants were actively preparing to enrol in university. Others took the initiative to seek assistance from university staff rather than waiting for services to be offered. Chen also reported that for those who had held professional employment before immigration, their dreams of reconstructing a professional identity never died. Despite the self-repression, compromises, and sacrifices they made over the years, almost all the participants looked forward to returning to the workplace after their husbands graduated and their children grew up. It seems that positive hopes and expectations for the future served as a catalyst to engage in proactive behaviour in order to overcome some of the immediate pressures. This kind of agency was also demonstrated in the study conducted by Zhang, Smith, Swisher, Fu, and Fogarty (2011), in which Chinese APIS were reported to look for every chance to improve their English fluency and prepare for university entrance.

The excessive concern with problematic adjustment may be obscuring important aspects of how APIS cope with adversity during the cross-cultural transition. Similar to the general literature on international students, there is an abundance of research that refers to adjustment concerns in general, without examining specific stressors and ways of coping. Rather than viewing APIS's adaptation as deficit-based, researchers could examine how they manage to overcome such adversities. International sojourns are not a static process. Rather, over time, there are bound to be ebbs and flows in the cross-cultural transition experience, and in how well different APIS cope with specific demands (Arthur, 2016). It is also important not to decontextualize their experiences from their marital and family situation. The perceptions of coping with and adapting to stress are related to how well international students and their partners are able to individually address perceived demands, and how they are able to rally their resources as a couple, and as a family.

Although stories about agency and resilience are very limited in the APIS literature, they are like sunshine after a rainy day, or a lighthouse in a storm-dark sea. More research in this area is needed, which could provide the other side of the story to overcome the unbalanced, pessimistic, and pathological view that dominates the field. Human agency versus structural determinations has been argued as one of the four fundamental questions of sociological debates (Wotherspoon, 2009). As Giddens (1987) noted: "we create society at the same time as we are created by it" (p. 11). Instead of overemphasizing either one of them, researchers need to explore how APIS and social structures in the host societies mutually influence each other, a fundamental premise for understanding the acculturation process (Berry, 2001). Although it appears that the balance may currently be tipped towards how this group navigates local systems and resources, it is prudent to remember that the hosting countries have a responsibility to extend a welcome to newcomers who accompany international students.

\section{Issue Two: Gender and Other Ignored Social Constructs}

\section{Gender Issues}

For APIS, accompanying their male partners who choose to study abroad means facing challenges of "double adjustment" (de Verthelyi, 1995). In addition to social and cultural adaptation difficulties, many of them have to deal with gender-based role expectations. At the same time, their experiences may be compounded by their loss of professional jobs in the host country, which influences their immigration decision, career plans, marital re- 
lationship, and self-identification in many ways. Our review of the literature showed that gender issues were pervasive amongst participants.

In Chen's (2009) study of international graduate students' wives in the USA, she found that some participants took the decision to accompany their husbands to go abroad as a must, based on the belief that "women need to compromise" or "women need to follow husbands whenever husbands go" (p. 224). In assuming a subordinate position in relation to their husbands, these women took the patriarchal gender relation for granted without giving equal consideration to their own life opportunities in the new country. This unequal gender relationship can be further exacerbated by systemic constraints and familial limitations that prevent APIS from pursuing professional jobs and educational opportunities in the host country. For example, in some countries, immigration policies may restrict non-student, non-immigrants from obtaining employment. This is particularly true in the United States, where APIS holding F2 visas are not allowed to work (Myers-Walls et al., 2011). A quotation from one of the participants in Kim's (2012) study best demonstrates this point: "[for me] to get a job, my husband would need to get a job first and then change our visa status. It is very complicated. So, the fact that I could not work made me depressed and anxious" (p. 759). In contrast, partners of full-time international students can apply for study and work permits in Canada (Citizenship and Immigration Canada, 2013). The possibility of pursing employment has a major influence on whether or not this group is able to express important parts of their identities and continue to gain valuable employment experience. Depending on the level of employment, international work experience may have tremendous value for those international students and partners who return home or who want to pursue permanent immigration (Arthur \& Flynn, 2011).

The specific legal and employment policies that exist in different social contexts have important implications for the adaptation process of APIS, particularly given the fact that many of their adjustment issues have been found to be associated with their lack of employment. Even if there are employment or education opportunities available in the host country, APIS may put their own career aspirations and plans on hold due to familial limitations such as childcare responsibilities and financial constraints. In their study of APIS in a western Canadian university, Martens and Grant (2008) reported that although participants were interested in advancing their studies, few were able to do so. The expense associated with paying international student tuition fees for a second member of the family was ranked as the largest barrier that deprived these women of further educational opportunities. In fact, only $7 \%$ of participants were enrolled in university or college courses. Although 38\% managed to obtain employment, they were unable to find a position in the fields in which they were trained; instead, they had to work in service industries with low job satisfaction, such as house cleaning and childcare provision. For those who have children, financial difficulty and the absence of extended family members to assist with child-rearing may force them to give up their own career plans to take care of their families. Others may unconsciously accept the gendered work division that prescribes women as caregivers and men as breadwinners, thereby prioritizing their nurturing role over their career goals (Chen, 2009; Cooke, 2007). As a consequence, although many APIS are well-educated and well-paid professionals in their home countries, they may experience varying degrees of "career gap or vacuum" in the host country, characterized by unemployment or underemployment. 
Not surprisingly, the loss of professional employment, and its associated financial independence and social status, causes many APIS to struggle with their identity in a new environment. This is often characterized by a sense of underachievement, self-doubt, and low self-esteem. It presents particular challenges for those who were socialized in societies with the dominant gender ideology defining a normal woman as a career woman who should work until retirement (Chen, 2009). For example, in their studies of wives of Chinese international students in the USA, Zhang et al. (2011) reported participants had to cope with a disruption of gender roles, which is conceptualized as an identity conflict between a dependent, domestic, and subordinate gender role in the host country and a more egalitarian gender ideology in the home country.

For APIS, the loss of their professional employment means not simply an identity struggle in the discursive dimension, but rather an actual power dynamic that has material consequence in their everyday lives. More specifically, it contributes to unequal power relations between husbands and wives as a form of financial control. In Zhang et al.'s (2011) study, one participant expressed concerns that her husband restricted her financially: "At the beginning [in the USA], my husband did not limit me from spending money, later he always reminded me that I spend too much money . . . I feel uncomfortable because I cannot spend money according to my wishes" (p. 532). For others, the gender-based unequal power relation is manifested at the level of family decision making. For example, in Chen's (2009) study, one participant reported that her original plan to be a babysitter was rejected by her husband, and she finally had to obey his suggestion to stay at home to take care of their son and prepare for her nursing licensure exam. In another case, a participant reported the whole family immigration plan was decided by her husband, who preferred to build his career in the USA after graduation; although she wanted to return home, as she could not find any employment except working part-time at a restaurant (Myers-Walls et al., 2011).

Unequal gender relationships also emerge in husbands' gender-based expectations of wives in their domestic work division. As noted previously, the academic demands perceived by international students may leave them little time to devote to their accompanying partner or household. Consequently, APIS may be expected to shoulder all the housework. In some cases, this unpaid labour is undervalued, taken for granted, and critically judged by their husbands. For example, one participant in Myers-Walls et al.'s (2011) study described the meaning she associated with the complaints that her husband had about her cooking: "it seems that your value is reflected by whether the meal is good" (p. 533). Interestingly, although some husbands appreciated the domestic work their wives did, it was the women themselves who devalued their roles, expressed as feeling "I did nothing" (p. 220). Examples such as these suggest that some APIS themselves accept the gendered ideology that devalues domestic work in the larger society.

The gendered beliefs and values that view women as weak, passive, and obedient may further restrict APIS from taking the initiative to search for possible resources and make changes in the face of difficulties and challenges in the new living environment. In Chen's (2009) study dealing with adaptation barriers, the most common strategies used by APIS were repressing, enduring, and transferring their focus to alternatives. More specifically, they may experience various types of suffering, such as loneliness and depression, simply by convincing themselves to endure the situation longer. They may participate in a vari- 
ety of activities, such as volunteering to keep themselves busy and to overcome negative thoughts and feelings. However, as Chen argued, such passive coping strategies and attitudes of negotiation, characterized by enduring and accepting existing limitations, reflect the long-term oppression of women in various societies.

\section{It's Not Only About Gender: The Intersections of Class and Race}

The various adaptation issues that APIS encountered in the host country cannot simply be viewed as an individual experience; rather, they reflect broader social relations based on race, gender, class, and other socially constructed differences. Our review of the literature shows that existing studies on this population tend to overwhelmingly focus on gender issues in isolation. What is missing from this kind of research is how gender interacts with other socially constructed differences, such as race and class, that lead to APIS's divergent life trajectories.

Racialized identities. For many APIS, the process of racialization may be a new experience that occurs during their cross-cultural transition. They may not realize local people will view them as members of racialized minorities until they arrive in the country where their international partners are studying (Arthur, 2004). Racist beliefs and values are deeply embedded in the social structure and collective unconsciousness of Western countries (Cui, 2015; Cui \& Kelly, 2013). As Henry, Tator, Mattis, and Rees (2006) poignantly argued, two contradictory value systems coexist in contemporary Canadian society, and these manifest as a paradox in the minds of many Canadians: on the one hand, some Canadians embrace democratic values and fairness, while on the other hand, they continue to hold racist beliefs towards others.

Racism is not only individual but systemic and institutional. Research on immigrants reveals that racialized minorities have experienced tremendous barriers when trying to access Canadian labour markets, such as non-recognition or devaluation of their foreign credentials, lower income than their Canadian counterparts with similar qualifications, and the glass-ceiling problem in job promotion (Basran \& Zong, 1998; Guo, 2013; Li, 2003). Research with international students has also surfaced barriers to them entering the labour market, such as devaluation of experience in their home country, perceived racism in the interview process, and preference for local experience (Arthur, 2013).

A review of literature shows that APIS, especially those who are members of racialized minorities, have similar experiences. For example, Cooke (2007) reported a Chinese APIS in Britain complaining that although she exhibited better academic performance than her classmates in the accounting program, employers would hire her classmates instead of her because of "her Chinese background" (p. 60). APIS in Teshome and Osei-Kofi's (2012) study felt that they were not accepted as part of the local community, even though they had lived there for years. One participant from Kazakhstan, who had stayed in a university town for six years, noted the culture of the community made her feel "uncomfortable or different," as "people are always with someone who looks like them" (pp. 66-67). In contrast, another participant from Holland felt people were nice there but was "not sure if other women [who were non-Europeans] feel the same way" (p. 67). Although the issue of racial discrimination is identified in some of the literature, it is often discussed briefly and superficially. What has not been adequately researched is how racism affects APIS's lived experiences, particularly their identity construction, educational plan, and career transi- 
tion at a deeper level. Rather than treating the topic of racism as a taboo, we need more research in this regard if researchers, policy makers, and university staff are really willing to address the difficulties APIS experience from a social justice perspective. In turn, personnel who work with international students and their accompanying partners need to be willing to introduce conversations about the lived experience of racism and help individuals to process such experiences in light of the potential impacts (Arthur, 2016). Beyond focusing on the individual, local campuses and communities need to be better prepared for receiving individuals from diverse cultures and countries, which will lead to a more welcoming host society (Arthur, 2004).

Social class influences. Little research has explored how APIS's socioeconomic backgrounds affect their specific life choices and decisions in the host country. Ataca and Berry's (2002) quantitative study with Turkish immigrant couples in Toronto identified a correlation between their acculturation and socioeconomic status as well as gender. More specifically, they found women in general were more psychologically vulnerable than men, and this gender difference was more apparent in the low socioeconomic status group; women with low socioeconomic status experienced a more difficult time than men in coping with psychological adaptation. Despite the importance of this kind of research, it is worthwhile noting that the social class issue means more than the type and volume of economic capital one has. It is also about the internalized social structure or social disposition that is acquired from one's past experiences in specific social contexts. It is reflected in ways of doing, thinking, and being that either benefit or hinder the individual social agent and his/her perceived life opportunities in a particular field (Bourdieu, 1994). Such an understanding of social class sheds important light on research about APIS. Taking their educational and career choices as an example, researchers could explore at a deeper level how their past experiences and upbringing in certain circumstances helped to shape their outlooks and beliefs as well as their present and future practices. In other words, it would be interesting to know how their "habitus" (Bourdieu, 1994) acquired from their class positions may guide them towards particular social positions in the new living environment as well as towards certain practices and goods that befit them in that position. It would also be interesting to know how one's specific type of habitus interacts with different forms of capital one accumulates, such as language and cultural preference, social networks, and family income, and how these affect accompanying partners' coping strategies as well as their future career and immigration plans.

Although we discuss race, gender, and social class separately in this paper, they are not exclusive and independent categories. The complexity of APIS's adaptation experiences and the multilayered social oppression that they may encounter in the host society cannot be fully examined or explained in separate and/or additive analyses. Rather than having a dichotomous model of thought and treating social oppression in either/or categories, researchers need to understand social oppression as multiplicative and intersecting (Dei, 2005).

\section{Issue Three: Conflation of Different Populations and Heterogeneity}

The third issue with research on APIS focuses on the problem of homogeneity and essentialism. Due to the limited existing research, studies on this population tend to draw comparisons from the literature on the trailing partners of expatriates, or to combine APIS 
with immigrants as the targeted population of research. Our review of the literature showed some similar adaptation issues between these different groups. Topics examined in the research on trailing partners of expatriates included (a) the influence of trailing partners in the adjustment of expatriate managers (Lauring \& Selmer, 2010); (b) the adaptation difficulties that trailing partners encounter (e.g., psychological distress) (Birdlebough, 1998; Shaffer \& Harrison, 2001); (c) career issues of dual-career couples in their relocation decision (Harvey, 1997; Shahnasarian, 1991); (d) gender issues (Braseby, 2010; Cole, 2012); and (e) program development and organizational support for dual-career couples in their foreign assignment (Copeland \& Norell, 2002; Harvey, Buckley, Novicevic, \& Wiese, 1999). Despite the similarities between APIS and trailing partners of expatriates, the two groups are in totally different situations. Social status and income are what often make APIS distinct (Martens \& Grant, 2008). Unlike trailing partners of expatriates in business families, who may enjoy a status promotion, income increases, and beneficial compensations when being sent abroad by international companies and government agencies, international students' families tend to experience financial constraints and income instability (e.g., limited resources made available to international students through research or teaching assistantships or academic scholarships). As de Verthelyi (1995) noted, many international students' families suffer from a reduced budget due to increasing tuition and diminishing university funds. This situation may be further exacerbated by the employment status of international students' accompanying partners. As a consequence, they may find themselves struggling with lower living standards than in their home country. Undoubtedly, a shrinking and unstable family income and a decrease in social status will cause more adaptation difficulties for APIS than for trailing partners of expatriates.

International students and their partners also differ from immigrants, who have access to various government benefits, such as social welfare, made available by virtue of their permanent resident or citizenship status. In most receiving countries, the tuition fees for international students are often at least double the fees paid by immigrants. As well, unlike immigrants, who have decided to settle down in the host country, many international student families are not certain whether they will return home or stay in the host country after graduation. Their plans depend on many factors, including immigration policies and employment opportunities in the host country, language and cultural adaptation, and their children's education. This uncertainty about the future may cause additional psychological stress for international student families (Myers-Walls et al., 2011).

Further, APIS are not a homogenous group. Although members in this group may share some common adaptation issues or be inculcated with similar (gender) ideology in their home countries, they are also differentiated from each other in terms of socioeconomic status, ethnic origin, age, ability, and other social constructs. Even for those who come from the same country, their different social positions may lead them to divergent life trajectories and choices. An essentialist perspective assumes the experience of being a member of a group has a clear and fixed meaning (Grillo, 1995). For example, studies on APIS may tend to generalize the experience of Korean APIS or how Chinese APIS make career plans. Such an essentialist approach not only ignores the heterogeneity within any single ethnic group, which is mediated by divergent social constructs, but also treats such ethnic groups as real, having a substantial essence that remains unchanging through time and space. Therefore, an essentialist "groupism" is problematic (Brubaker, 2002). On the other hand, we argue 
that researchers should also not accept a radical individualist approach that regards the marginalization that APIS experience simply as individual experiences; such a perspective ignores the group-based historical struggles that this population may have collectively experienced in the contemporary host societies and may still be experiencing. Rather than taking an either/or approach, we call for researchers to try to understand APIS's experiences and issues in "relational, processual and dynamic" terms (Brubaker, 2003, p. 555). More specifically, this requires treating their ethnic group as "a contextually fluctuating conceptual variable" rather than a fixed entity (p. 555). Additional research is needed to address the complexity and heterogeneity of this group while attending to their common issues.

\section{Recommendations for Future Research}

In this review paper, we have identified three major issues with existing studies on the APIS: (a) adaptation difficulties and human agency; (b) gender and other ignored social constructs; and (c) conflation of different populations and heterogeneity. We argue that existing studies on this population tend to overwhelmingly focus on social constraints and adaptation difficulties, particularly from a deficit approach. What is missing from the research to date is an exploration of how APIS exercise human agency when making adaptation and career transitions. We also point out that research on APIS should go beyond an overemphasis on gender to comprehensively analyze how gender intersects with other inequitable social relations such as race and class in contributing to the complexity, multiplicity, and intersectionality of marginalization and subordination that they may confront in the host society. Further, we suggest that rather than conflating APIS with trailing partners of expatriates or immigrants and treating these three populations as a homogenous group, researchers should address the issue of heterogeneity from an anti-essentialist approach.

Based on our conclusions, a number of questions arise as possible areas for future reflection and research. Particularly, we suggest central questions that specifically address the three issues that we identified in the previous discussion. We also expand on these key directions with related sub-questions. In framing these questions, we have added a particular focus on the career transition of APIS, which has not been adequately researched within the existing literature. The motivations for moving to another country may be primarily focused on the international students, but the career trajectories of their accompanying partners are also impacted. Using this central focus as a way to frame many of the following questions will not only help APIS move from the background to the foreground of research, but will also make more visible their career-related needs.

\section{Questions to Inform Future Research on APIS}

1. Despite their adaptation and settlement difficulties, how do APIS exercise agency to overcome various barriers in the host country?

Sub-questions: How do they successfully achieve their career transition goals in a new living environment? What strategies do they use? What can we learn from those successful cases? Have they ever sought formal support, such as counselling services? If so, what are their opinions and expectations in terms of improving existing counselling services in order to better serve this population? 
2. How do race, gender, class, and other socially constructed differences intersect with each other in affecting the lived experiences of APIS in a new country?

Sub-questions: Does race matter in their adaptation and career transition in the host society? If it does, then how does racism affect APIS's lived experiences and career trajectories? How have they responded to any experience of racism? How does their socioeconomic status affect their adaptation strategies and career transitions in the host country, particularly in terms of making certain educational and career choices while rejecting others? How do gender influences affect them in designing their short-term and long-term career goals and paths? How do they negotiate gender relations and gender roles within the family to realize their transition into a new living environment? Most importantly, how should we examine and interpret their lived experiences as both individuals and groups?

3 . What are the resources and support systems that APIS perceive would be necessary for them to successfully navigate living within a Canadian cultural context?

Sub-questions: What are the support systems that would help APIS to pursue their educational and career goals while living in the Canadian context? What is needed for Canadian postsecondary institutions to expand their service programs from international students to their partners? How could Canadian postsecondary institutions move from simply providing services to facilitating this group to attend and benefit from those services? What are the institutional supports or community-based services that they may find to be helpful?

Based on our review of the literature on the experiences of APIS in various different host cultures, we believe future research based on these questions will greatly enrich and expand current scholarship about this population theoretically, methodologically, and practically.

\section{Conclusion}

Through this paper, we aim to draw more academic attention to APIS, an often ignored population who embark on a major cross-cultural transition due to their partners' education. This goal is timely, particularly during an era when internationalization and international student recruitment is a strategic priority for many Canadian institutions in higher education. Unlike international students, who are often placed in the spotlight of the internationalization research, accompanying partners are frequently ignored by both the administration and researchers in higher education. Rather than APIS being left to struggle in the shadows, the challenges they face based on unequal social relations such as race, gender, and class must be tackled from a social justice perspective. Many international students' partners are well-educated professionals in their home country, and their experience may be vital to their family's decision to pursue permanent immigration. Therefore, obtaining an understanding of APIS's concerns and providing them with necessary educational and employment opportunities will not only help international student families and facilitate the internationalization of Canadian higher education, but may also serve this country's long-term goal of recruiting highly skilled immigrants. The themes that we have identified in this paper attest to the multiplicity of issues and systemic influences that impact the social and economic well-being of accompanying partners, including factors that are inextricably tied to the decision to pursue longer-term immigration. 


\section{Acknowledgement}

The first author would like to acknowledge funding provided through the Eyes High Postdoctoral Fellowship at the University of Calgary during which this paper was drafted and submitted under the supervision of the second author. The authors would like to acknowledge the Social Sciences and Humanities Research Council of Canada, which provided support for this research (Insight Development Grant \#430-2014-00020). The authors would also like to acknowledge the comments of the anonymous reviewers.

\section{References}

Advisory Panel on Canada's International Education Strategy. (2012). International education: A key driver of Canada's prosperity. Ottawa, ON: Foreign Affairs and International Trade Canada. Retrieved from http://www.international.gc.ca/education/ report-rapport/strategy-strategie/index.aspx?view=d

Arthur, N. (2004). Counselling international students: Clients from around the world. New York, NY: Springer.

Arthur, N. (2013). International students and career development: Human capital in the global skills race. Journal of the National Institute for Career Education and Counselling, 31, 43-50.

Arthur, N. (2016). Counselling international students in the context of crosscultural transitions. In J. Draguns, W. Lonner, P. Pedersen, J. Trimble, \& M. Scharrón del Río (Eds.), Counselling across cultures (7th ed., pp. 301-322). Thousand Oaks, CA: Sage.

Arthur, N., \& Flynn, S. (2011). Career development influences of international students who pursue permanent immigration to Canada. International Journal of Education and Vocational Guidance, 11, 221-237. doi:10.1007/s10775-011-9212-5

Ataca, B., \& Berry, J. W. (2002). Psychological, sociocultural, and marital adaptation of Turkish immigrant couples in Canada. International Journal of Psychology, 37(1), 13-26.doi:10.1080/00207590143000135

Basran, G., \& Zong, L. (1998). Devaluation of foreign credentials as perceived by visible minority professional immigrants. Canadian Ethnic Studies, 30(3), 6-18.

Berry, J. (2001). A psychology of immigration. Journal of Social Issues, 57, 615-631. doi:10.1111/0022-4537.00231

Birdlebough, S. L. (1998). Determinants of trailing spouses' well-being in geographically mobile dual-career couples (Order No. 9905863). Available from ProQuest Dissertations \& Theses Full Text; ProQuest Dissertations \& Theses Global. (304468151).

Bourdieu, P. (1994). In other words: Essays towards a reflexive sociology. Cambridge, UK: Polity Press.

Braseby, A. M. (2010). Adaptation of trailing spouses: Does gender matter? (Order No. 3470212). Available from ABI/INFORM Complete; ProQuest Dissertations \& Theses Full Text; ProQuest Dissertations \& Theses Global. (744523637).

Brubaker, R. (2002). Ethnicity without groups. European Journal of Sociology, 43, 163-189. doi:10.1017/Sooo3975602001066 
Brubaker, R. (2003). Neither individualism nor "groupism": A reply to Craig Calhoun. Ethnicities, 3, 553-557. doi:10.1177/1468796803003004006

Canadian Bureau for International Education. (2013). A world of learning: Canada's performance and potential in international education 2013. Retrieved from http://net. cbie.ca/download/CBIE\%2oFlagship\%202014\%20E\%20-\%20WEB\%2oRES\%2ofinal.pdf

Chen, L. (2009). Negotiating identity between career and family roles: A study of international graduate students' wives in the US. International Journal of Lifelong Education, 28, 211-226. doi:10.1080/02601370902757075

Cho, K. C., Lee, J., \& Jezewski, M. A. (2005). Korean women living in the United States as student wives. Health Care for Women International, 26, 897-915. doi:10.1080/07399330500301838

Citizenship and Immigration Canada. (2013). Help your spouse or common-law partner work in Canada. Retrieved from http://www.cic.gc.ca/English/study/workspouse.asp

Cole, N. D. (2012). Expatriate accompanying partners: The males speak. Asia Pacific Journal of Human Resources, 50, 308-326. doi:10.1111/j.1744-7941.2012.00024.x

Cooke, F. L. (2007). "Husband's career first": Renegotiating career and family commitment among migrant Chinese academic couples in Britain. Work, Employment and Society, 21(1), 47-65. doi:10.1177/0950017007073615

Copeland, A. P., \& Norell, S. K. (2002). Spousal adjustment on international assignments: The role of social support. International Journal of Intercultural Relations, 26, 255-272. doi:10.1016/So147-1767(02)0oo03-2

Cui, D. (2015). Capital, distinction and racialized habitus: Immigrant youth in the fields of Canadian schools. Journal of Youth Studies, 18(9), 1154-1169. doi:10.1080/136 76261.2015 .1020932

Cui, D., \& Kelly, J. (2013). “Too Asian?” or the invisible citizen on the other side of the nation? The Journal of International Migration and Integration, 14(1), 157-174.

de Verthelyi, R. F. (1995). International students' spouses: Invisible sojourners in the culture shock literature. International Journal of Intercultural Relations, 19, 387-411.

doi:10.1016/0147-1767(95)ooo28-A

Dei, G. (2005). The intersections of race, class, gender in the anti-racism discourse. In V. Zawilski \& C. Levine-Rasky (Eds.), Inequality in Canada: A reader on the intersections of gender, race and class (pp. 17-35). Don Mills, ON: Oxford University Press.

Fonseca, M. E. (1995). Factors related to parenting stress and satisfaction among international students with accompanying families and their spouses (Order No. 9601494). Available from ProQuest Dissertations \& Theses Full Text; ProQuest Dissertations \& Theses Global. (304233794).

Giddens, A. (1987). Sociology: A brief but critical introduction (2nd ed.). San Diego, CA: Harcourt Brace Jovanovich.

Grillo, T., 1995. Anti-essentialism and intersectionality: Tools to dismantle the master's house. Berkeley Women's Law Journal, 10, 16-30. 
Guo, S. (2013). Economic integration of recent Chinese immigrants in Canada's second-tier cities: The triple glass effect and immigrants' downward social mobility. Canadian Ethnic Studies, 45(3), 95-115. doi:10.1353/ces.2013.0047

Harvey, M. (1997). Dual-career expatriates: Expectations, adjustment and satisfaction with international relocation. Journal of International Business Studies, 28, 627-658. doi:10.1080/095851999340161

Harvey, M., Buckley, M. R., Novicevic, M. M., \& Wiese, D. (1999). Mentoring dualcareer expatriates: A sense-making and sense-giving social support process. International Journal of Human Resource Management, 10, 808-827. doi:10.1080/095851999340161

Henry, F., Tator, C., Mattis, W., \& Rees, T. (2006). The color of democracy: Racism in Canadian society (3rd ed.). Toronto, ON: Thomson Nelson.

Kim, J. (2012). Acculturation phenomena experienced by the spouses of Korean international students in the United States. Qualitative Health Research, 22, 755-767. doi:10.1177/1049732311431442

Lauring, J., \& Selmer, J. (2010). The supportive expatriate spouse: An ethnographic study of spouse involvement in expatriate careers. International Business Review, 19(1), 59-69. doi:10.1016/j.ibusrev.2009.09.006

Li, P. S. (2003). Destination Canada: Immigration debates and issues. Don Mills, ON: Oxford University Press.

Martens, V. P., \& Grant, P. R. (2008). A needs assessment of international students' wives. Journal of Studies in International Education, 12(1), 56-75. doi:10.1177/1028315306293547

Myers-Walls, J., Frias, L. V., Kwon, K., Ko, M. M., \& Lu, T. (2011). Living life in two worlds: Acculturative stress among Asian international graduate student parents and spouses. Journal of Comparative Family Studies, 42, 455-478.

Schwartz, C. G., \& Kahne, M. J. (1993). Support for student and staff wives in social transition in a university setting. International Journal of Intercultural Relations, 17, 451-463. doi:10.1016/0147-1767(93)90004-R

Shaffer, M. A., \& Harrison, D. A. (2001). Forgotten partners of international assignments: Development and test of a model of spouse adjustment. Journal of Applied Psychology, 86, 238-254. doi:10.1037/0021-9010.86.2.238

Shahnasarian, M. (1991). Job relocation and the trailing spouse. Journal of Career Development, 17, 179-184. doi:10.1007/BFo1322025

Teshome, Y., \& Osei-Kofi, N. (2012). Critical issues in international education: Narratives of spouses of international students. Journal of Studies in International Education, 16(1), 62-74. doi:10.1177/1028315311403486

Wills, P. (1977). Learning to labour: How working class kids get working class jobs. New York, NY: Columbia University Press.

Wotherspoon, T. (2009). The sociology of education in Canada (3rd ed.). Oxford, UK: Oxford University Press. 
Zhang, J., Smith, S., Swisher, M., Fu, D., \& Fogarty, K. (2011). Gender role disruption and marital satisfaction among wives of Chinese international students in the United States. Journal of Comparative Family Studies, 42, 523-542.

\section{Contact Information}

Dan Cui

Graduate School of Education

University of California, Berkeley

danc@berkeley.edu ordan.cui@ubc.ca

Dr. Dan Cui is a SSHRC Postdoctoral Fellow, jointly affiliated with the University of California, Berkeley, Graduate School of Education and the University of British Columbia, Department of Educational Studies. Her research interests include immigration and integration, with a particular focus on immigrant youth and international students, social justice and equity in education, sociology of education, school/university-to-work transition, and international and comparative education. She has recently published in the Journal of International Migration and Integration, Canadian Ethnic Studies, and the Journal of Youth Studies.

Dr. Nancy Arthur is a Professor and Associate Dean Research, Werklund School of Education, University of Calgary. Nancy's research interests include professional education for diversity and social justice, and international work and learning transitions. Nancy held a Canada Research Chair from 2004 to 2014 and received the Distinguished Researcher Award from the Werklund School of Education in 2015. Nancy currently serves on the Board of Governors for the Canadian Career Development Foundation and as a Vice-President for the International Association of Educational and Vocational Guidance.

Dr. José F. Domene is a Professor and Canada Research Chair (Tier 2) in School-to-Work Transition in the Faculty of Education at the University of New Brunswick. His areas of research interest include relational contexts of career development, emerging adults' transition into the workforce, and professional issues in counselling and counselling psychology in Canada. He is also a licensed psychologist whose clinical practice focuses on the career and mental health needs of university students, particularly international students. 


\section{Appendix A}

Sample of Literature Review Table

\begin{tabular}{|c|c|}
\hline $\begin{array}{l}\text { len, L. }(2009) .1 \\
\text { rnational gradua } \\
\text { tion, } 28(2), 211\end{array}$ & $\begin{array}{l}\text { iating identity between career and family roles: A study of in- } \\
\text { udents' wives in the US. International Journal of Lifelong Edu- } \\
\text { - }\end{array}$ \\
\hline Topic/Issues & $\begin{array}{l}\text { Identity negotiation between career and family roles among inter- } \\
\text { national graduate students' wives in the United States. }\end{array}$ \\
\hline Research Questions & $\begin{array}{l}\text { 1. How did international graduate students' wives (IGSWs) } \\
\text { arrange their lives as they paused or even stopped their } \\
\text { work careers when they decided to accompany their hus- } \\
\text { bands to the United States? } \\
\text { 2. How did IGSWs negotiate their identities when they be- } \\
\text { came full-time housewives in a foreign country? } \\
\text { 3. How did IGSWs' cultural background impact the process of } \\
\text { identity negotiation? }\end{array}$ \\
\hline Methods & $\begin{array}{l}\text { Qualitative research design, semi-structured interview questions } \\
\text { (open-ended with follow-up probes and questions), 60-90 minutes. } \\
\text { Nine IGSWs, non-American, between the ages of } 25 \text { and } 45 \text {, located } \\
\text { at a southeastern university in the United States. Participants' only } \\
\text { reason for coming to and staying in the USA was their husbands' } \\
\text { pursuit of doctoral degrees. } \\
\text { All participants had finished at least their college education in their } \\
\text { mother country (two had completed master's degrees), USA. All } \\
\text { participants had been housewives in the USA for more than a year. } \\
\text { All participants were the same nationalities as their husbands with } \\
\text { the exception of one (the respondent from Mexico). } 2 \text { were Chinese, } \\
2 \text { Korean, } 1 \text { Indian, } 1 \text { Mexican, } 1 \text { Nepalese, } 1 \text { Singaporean, and } 1 \text { Tai- } \\
\text { wanese. } \\
\text { Five participants came to the USA pregnant or with one baby or } \\
\text { pre-school child. }\end{array}$ \\
\hline
\end{tabular}




\begin{tabular}{|l|l|}
\hline Findings/ \\
Conclusions & $\begin{array}{r}\text { 1. The relationship self dominated in the IGSWs' decision to } \\
\text { accompany their husbands. The desire to be with their hus- } \\
\text { bands was a main concern and seen as a must. The hus- } \\
\text { band's future career and family needs came first. } \\
\text { 2. Repressing/enduring and transferring focus (i.e., focusing } \\
\text { on parenting) were the most common identity negotiation } \\
\text { strategies. Participants with children lost mobility, which } \\
\text { resulted in reduced independence, limited involvement in } \\
\text { activities, and ensuing depression. All wanted more than } \\
\text { their role as a housewife and did not enjoy this singular } \\
\text { role. These challenges created difficulties with negotiating } \\
\text { identity. } \\
\text { 3. While native culture played a part, other factors were } \\
\text { equally important or even transcended the cultural norm in } \\
\text { the process of the IGSWs'identity negotiation. Personality, } \\
\text { strong sense of self, original family background, life stage, } \\
\text { and life history did not transcend the definitions of women } \\
\text { and housewives resulting from the native culture. }\end{array}$ \\
$\begin{array}{l}\text { Relationships, cultural values and backgrounds were significant } \\
\text { forces impacting decision making, adaptation, and identity ne- } \\
\text { gotiation for IGSWs. Participants did not want their lives to be } \\
\text { limited by family and their role as housewife, and they looked for- } \\
\text { ward to returning to the workplace after their children grew up } \\
\text { and their husbands graduated. }\end{array}$ \\
\hline $\begin{array}{l}\text { None listed } \\
\text { Gaps/Future } \\
\text { Direction for }\end{array}$ & $\begin{array}{l}\text { Providing information on related support and resources on and } \\
\text { off campus for international graduate students' wives. }\end{array}$ \\
\hline $\begin{array}{l}\text { Gaps/Future } \\
\text { Direction for }\end{array}$ & \begin{tabular}{l} 
Counselling \\
\hline
\end{tabular} \\
\hline
\end{tabular}

